\title{
11
}

\section{PREFERENCE EROSION: THE CASE OF FIJI SUGAR}

Satish Chand

Preference erosion refers to a situation where exporters with privileged access to specific markets lose their competitive advantage as barriers to trade in their export markets are lowered to third-country exporters. The case considered here is that of sugar exports from Fiji into the European Union under the Sugar Protocol. Exports of specified quantities of raw sugar from the African, Caribbean and Pacific (ACP) states to the European Community under the Cotonou Agreement enjoy guaranteed prices some two to three times the world market price. Preference erosion is a concern for the African, Caribbean and Pacific states given the impending liberalisation of the EU sugar regime. The decision in favour of the complainants, namely Australia, Brazil and Thailand, by the WTO panel on export subsidies to sugar by the EU could increase the pace of reform within the European Union and consequently accelerate the pace of preference erosion for the African, Caribbean and Pacific states.

Preference erosion is a serious issue for a number of developing countries. Yamazaki (1996), for example, notes that preferential imports into the European Union, United States, and Japan in 1992 accounted for 12 per cent of the total value of imports. The European Union as a destination and sugar as a product feature heavily in these discussions - the European Union, according to Yamazaki (1996), accounted for 73 per cent of the aggregate value of preferences, while sugar alone accounted for 46 per cent of the preference margin. Amongst the beneficiaries of preferential arrangements, Mauritius has 
consistently topped the list, with earnings from preferential access to its sugar exports into the European Union over the 2000-01 period amounting to 2.7 times what it would have earned if sold at the world market price; Fiji ranked eighth with earnings nearly double the value at world market prices (figures from Alexandria and Lankes 2004:Table 11.1). ${ }^{1}$ A number of studies confirm that the benefits of preferences are highly concentrated within a relatively small group of economies, thus the problems of preference erosion are, therefore, likely to be equally concentrated (Hoekman and Ozden 2005). As a result, reforms to the EuropeanUnion's sugar regime have the potential to draw significant interest from the WTO members who are likely to lose out in the process.

Fiji is particularly vulnerable to preference erosion. Sugar is a large sector that, as of 2001, accounted for some 7 per cent of GDP, 9 per cent of government revenues, 22 per cent of total exports, and the livelihood of nearly a quarter of the total population (Prasad and Narayan 2004). According to Page (2004), who draws on IMF estimates, a 40 per cent reduction in preference margins as a result of multilateral tariff reduction will result in a deterioration in the terms of trade of 8 percentage points for Fiji. An abrupt end to the sugar-preferences is likely to impose significant adjustment costs on the domestic economy, including a severe economic contraction, loss of government revenues, dislocation of households from rural to urban areas, and a worsening in the balance of payments position with consequences for the sustainability of the fixed exchange rate regime. These outcomes do not, as argued by Prasad and Akram-Lodhi (1998) and Oxfam (2002), constitute a case for continuation of the preferential arrangement, however. I argue here for assistance in the form of lump sum transfers equivalent in value to the rents implicit in the remaining life of the preferential arrangement to facilitate adjustment to a subsidy-free environment. The interventions considered here are specific to Fiji sugar but the principles have broader applicability.

This case study of Fiji sugar is illustrative of the issues and policy options in relation to preference erosion for six specific reasons.

- It concerns a commodity that is often claimed as one of the most distorted of internationally traded commodities (DFAT 2004; Oxfam 2002). The vast array of interventions in the global sugar market includes border tariffs, import quotas, and price guarantees.

- The study concerns the European Union, which is due to reform its sugar policy in the very near future, with ramifications for several African, Caribbean and Pacific countries. 
- Sugar is a homogenous product, making it possible to compute preference margins without the need for quality adjustments-an issue that has plagued similar studies for clothing and bananas.

- An amicable solution to preference erosion between the African, Caribbean and Pacific states and the rest of the WTO membership is likely to dissipate opposition to the Doha round of negotiations. The African, Caribbean and Pacific sugar producing states, ${ }^{2}$ for example, have joined a number of least developed economies to form the G-90 to block any further multilateral trade liberalisation that is likely to adversely affect their economies. Preference erosion was an issue of contention at the WTO ministerial meeting at Doha, particularly when the non-African, Caribbean and Pacific states objected to the request by the African, Caribbean and Pacific states for extension of the GATT waiver for their preferences. Panagariya (2003) contends that 'the fear on the part of the beneficiary countries that multilateral liberalisation would erode their preference margin has undercut their incentive to push harder for such liberalisation'.

- The small country assumption holds for Fiji in that changes in EU policies towards Fiji sugar are unlikely to have impacts beyond Fiji.

Table 11.1 Prices and quantities of sugar exports, 1990-2001

\begin{tabular}{|c|c|c|c|c|c|c|c|c|}
\hline Year & $\begin{array}{c}\mathrm{P}^{\mathrm{EU}(\mathrm{A})} \\
(\mathrm{F} \$)\end{array}$ & $\begin{array}{c}\mathrm{P}^{\mathrm{EU}(\mathrm{B})} \\
(\mathrm{F} \$)\end{array}$ & $\begin{array}{l}\mathrm{P}^{\mathrm{USA}} \\
(\mathrm{F} \$)\end{array}$ & $\begin{array}{l}\mathrm{P}^{\mathrm{WLD}} \\
(\mathrm{F} \$)\end{array}$ & $\begin{array}{l}\mathrm{Q}^{\mathrm{EU}(\mathrm{A})} \\
\text { (tons) }\end{array}$ & $\begin{array}{l}\mathrm{Q}^{\mathrm{EU}(\mathrm{B})} \\
\text { (tons) }\end{array}$ & $\begin{array}{c}\mathrm{Q}^{\mathrm{USA}} \\
\text { (tons) }\end{array}$ & $\begin{array}{l}\text { Total } \\
\text { exports } \\
\text { (tons) }\end{array}$ \\
\hline 1990 & 869.31 & n.a. & 621.95 & 351.08 & 157,891 & n.a. & 18,979 & 367,762 \\
\hline 1991 & 896.53 & n.a. & 635.33 & 336.05 & 182,799 & n.a. & 14,800 & 355,146 \\
\hline 1992 & 948.42 & n.a. & 532.92 & 333.19 & 197,740 & n.a. & 15,702 & 391,203 \\
\hline 1993 & 856.04 & n.a. & 664.42 & 343.61 & 182,033 & n.a. & 8,403 & 400,919 \\
\hline 1994 & 886.43 & n.a. & 615.97 & 362.85 & 169,055 & n.a. & 11,106 & 471,172 \\
\hline 1995 & 875.21 & 778.89 & 631.84 & 368.73 & 191,420 & 55112 & 10,197 & 412,011 \\
\hline 1996 & 902.66 & 771.87 & 935.79 & 364.10 & 137,554 & 30151 & 19,930 & 409,872 \\
\hline 1997 & 911.32 & 697.99 & 656.83 & 374.37 & 145,566 & 33733 & 18,980 & 303,118 \\
\hline 1998 & $1,110.20$ & 881.57 & n.a. & 293.66 & 189,180 & 31932 & - & 253,058 \\
\hline 1999 & 973.02 & 890.38 & 865.38 & 259.81 & 201,206 & 38448 & 18,513 & 336,437 \\
\hline 2000 & 941.48 & 768.44 & 724.11 & 410.56 & 176,471 & 20331 & 9,083 & 308,283 \\
\hline 2001 & 978.20 & 910.68 & 934.91 & 423.51 & 172,493 & 15700 & 9,065 & 243,873 \\
\hline
\end{tabular}

Notes: P denotes per-ton price, in Fiji current price dollars, for sugar exports under preferential quotas A, B, and to the United States, respectively.

Source: Primary data sourced from Fiji Sugar Corporation, 2002. 
- Finally, the study illustrates a case where rents have been dissipated through production inefficiencies. The withdrawal of EU sugar subsidies has been on the cards since 1986 when agriculture was first brought within the ambit of the GATT, and particularly since December 1994 following the European Union's commitment to limit the value of export subsidies (and the volume of subsidised sugar exports from the European Union) at the conclusion of the Uruguay Round. Preference erosion for African, Caribbean and Pacific sugar, therefore, is imminent.

The main findings of this chapter are that the rents from preferential access for sugar exports from Fiji have been large, amounting to nearly half the value of exports for the commodity and equal to some five per cent of GDP; the rents have been dissipated by inefficiencies in the growing of sugar cane and in the milling of the crop; a lump-sum transfer of the rents implicit in the remaining life of the preferential arrangement to sugar producers is likely to induce a rapid adjustment to a subsidy-free environment; and exposure of the domestic industry to world market prices is likely to improve resource allocation in the broader economy.

\section{PREFERENTIAL ARRANGEMENT FOR SUGAR}

Preferential access for Fiji sugar into the United Kingdom and subsequently into the European Union (after the United Kingdom joined the European Economic Community in 1974) has existed since the inception of the industry with indentured Indian labour in 1879. Sixty thousand workers, brought from India under the indenture scheme that lasted until 1916, subsequently formed the smallholder sector growing sugarcane on land leased from the indigenous population. Exports of sugar from Fiji to the European Union are governed by two trade agreements; namely, the Sugar Protocol and the Agreement on Special Preferential Sugar (SPS) between the African, Caribbean and Pacific states on the one hand and the European Union on the other. Article 1 of the Protocol states that

the [European] Community undertakes for an indefinite period to purchase and import, at guaranteed prices, specific quantities of cane sugar, raw or white, which originate in the African, Caribbean and Pacific states and which these States undertake to deliver to it.

The price, according to Article 5 of the Protocol, is to be negotiated annually; Article 3 specifies the country quotas; and Article 7 states that the quota is to be divided amongst the remaining members should a member fail to meet its 
allocation. The Protocol does not have a sunset clause and the European Union has reiterated its commitment (via the Cotonou Agreement) to continue importing specified quantities of sugar from the African, Caribbean and Pacific states at agreed prices. The SPS Agreement was enacted in 1995 with an initial term of six years to meet the sugar deficit among Portuguese refineries following the accession of Portugal and Spain to the European Union in 1986. Sugar sold under the SPS agreement earns around 85 per cent of the price paid under the Protocol. The United States has also given preferential entry to approximately 10,000 tons of sugar annually from Fiji under the Generalised System of Preferences (GSP).

The preferential arrangements transfer significant rents to Fiji via its exports of sugar to the European Union and the United States. As shown in Figure 11.1 and Table 11.1, under the Protocol the price received - net of transport costs and importer margins - for exports of sugar to the preferential markets for the 10-year period to 2001 earned a premium that was 2.6 times the world market price (referred to in the table as A-sugar), 2.3 times the world market price under the SPS Agreement (referred to in the table as B-sugar), and 1.9 times the world market price under the GSP. The Protocol accounted

Figure 11.1 Price of sugar exports to the European Union, United States and world market, 1990-2001

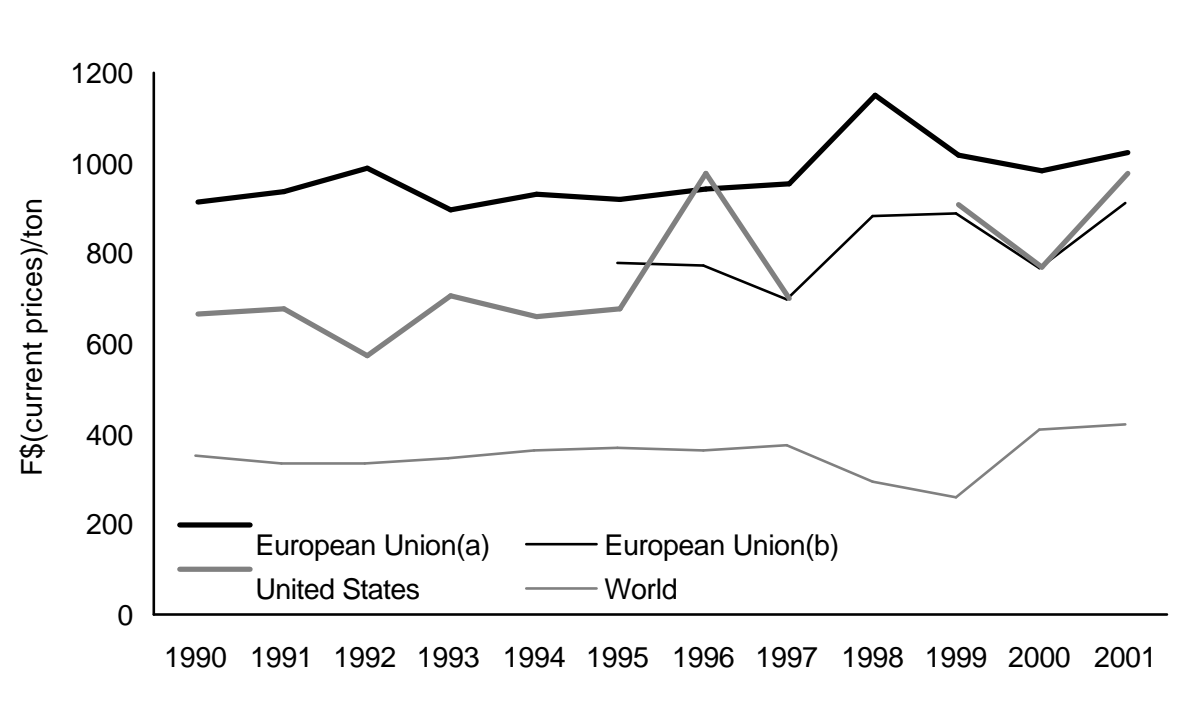


for some 90 per cent of the total quota rent-receipts, defined as the price premium multiplied by the preferential quota for the respective markets; SPS accounted for another six per cent, with the balance being accounted for by the GSP. For the 10 years to 2001, rents alone amounted to nearly half of the total value of exports of sugar; this equates to approximately five per cent of GDP (see Table 11.2).

The EU sugar regime has over the recent past come under attack on two specific grounds. First, while the European Union is self-sufficient in sugar, production within the European Union is alleged to entail large subsidies that in turn are claimed to disadvantage more competitive producers. Oxfam (2002:5), for example, reports that the production cost for a ton of white sugar in 2002 in Europe at $€ 673$ is nearly 2.4 times that of $€ 286$ for competitive producers such as Brazil, Colombia, Malawi, Guatemala and Zambia. Second, it is alleged the European Union has been dumping sugar on the world market. In 2002, for example, the European Union produced a total of 17 million tons of sugar and imported another 2.3 million tons, of which 1.5 million were imported from the African, Caribbean and Pacific states under preferential arrangements. Total consumption in the European Union in 2002 amounted to 12.7 million tons. Hence, some 7 million tons were exported. ${ }^{3}$ The debate on the impact of protection on world sugar, however, goes back to the early

Table 11.2 Sugar rents by source, 1990-2001

\begin{tabular}{lrcccc}
\hline Year & $\begin{array}{c}\text { EEC } \\
(\mathrm{F} \$ \mathrm{mn})\end{array}$ & $\begin{array}{c}\text { United States } \\
(\mathrm{F} \$ \mathrm{mn})\end{array}$ & $\begin{array}{c}\text { Total rents } \\
(\mathrm{F} \$ \mathrm{mn})\end{array}$ & $\begin{array}{c}\text { Rent/sugar } \\
\text { exports }(\%)\end{array}$ & $\begin{array}{c}\text { Rent/GDP } \\
(\%)\end{array}$ \\
1990 & 81.83 & 5.14 & 86.96 & n.a. & 5 \\
1991 & 102.46 & 4.43 & 106.88 & n.a. & 6 \\
1992 & 121.66 & 3.14 & 124.79 & 56 & 6 \\
1993 & 93.28 & 2.70 & 95.97 & 42 & 4 \\
1994 & 88.51 & 2.81 & 91.32 & 36 & 4 \\
1995 & 119.56 & 2.68 & 122.24 & 44 & 5 \\
1996 & 86.38 & 11.39 & 97.77 & 32 & 4 \\
1997 & 89.08 & 5.36 & 94.44 & 44 & 4 \\
1998 & 173.25 & - & 173.25 & 71 & 6 \\
1999 & 167.75 & 11.21 & 178.96 & 68 & 6 \\
2000 & 100.97 & 2.85 & 103.82 & 44 & 3 \\
2001 & 103.33 & 4.63 & 107.96 & 49 & 3 \\
\hline
\end{tabular}

Notes: Calculated using data sourced from Fiji Sugar Corporation, 2002 and Reserve Bank of Fiji Quarterly Review (various issues). 
1960s. Snape (1963) and Johnson (1964) were among the first to draw attention to the extent of protection, the ensuing rents to producers in the protected markets, and its impact on consumption and world market prices for the commodity. In his case for freer trade in sugar, Johnson (1966) argued that the ensuing efficiency gains could be used as foreign aid. He also pointed out that a deeper world market for sugar would reduce price variability.

Reforms leading to an erosion of the price premia within the Euroean Union have been long in coming. In its 1995 review of the sugar policy, the European Union clearly stated its intention to comply with its Uruguay Round commitments of 'substantial progressive reductions in agricultural support and protection'. ${ }^{4}$ The impetus for withdrawal of EU sugar subsidies may have been hastened by a recent WTO ruling in favour of Australia, Brazil and Thailand that the EU sugar subsidies were in excess of the levels agreed to in the Uruguay Round Agreement. ${ }^{5}$ The Cotonou Agreement lapses at the end of 2007, at which time preferential access to the EU market is due to be renegotiated. Any reforms of the EU sugar regime, including those arising from its commitment to WTO-sponsored rounds of multilateral trade liberalisation, will impact on the prices that African, Caribbean and Pacific states receive rather than market access for the guaranteed quantities of sugar into the European Union. African, Caribbean and Pacific states have received prices equal to those earned by sugar producers within the European Community; any liberalisation leading to a fall in the Community price of sugar will lead to preference erosion for the African, Caribbean and Pacific members.

\section{A SYNOPSIS OF THE FIJI SUGAR INDUSTRY}

Fiji sugar is produced from cane grown by a smallholder sector comprising some 21,000 farms with supply contracts to the Fiji Sugar Corporation (FSC). ${ }^{6}$ The average farm is 4.6 hectares in area and produces around 160 tons of sugarcane (data from Kingi 2004). The farms are run predominantly with family labour and with animal draught power. Sixty-one per cent of the farms produce less than 150 tons of cane per year, with 25 per cent harvesting less than 50 tons (data from Prasad and Akram-Lodhi 1998). All of the farms are rain-fed, and production varies considerably between years as a consequence. In good years, characterised by rainfall evenly spread throughout the growing season, sugarcane production has surpassed 4 million tons. ${ }^{7}$ 
Sugar is produced with aged technology. The sugarcane is manually harvested — much like when the industry was established 125 years ago-by some 14,000 cutters operating in small gangs. The cane is transported to one of the four sugar mills operated by the FSC. Approximately equal quantities of cane are transported via the rail system operated by the FSC and on privately operated motor trucks (lorries); the latter have increased as sugarcane cultivation has expanded into areas without rail transport (Sugar Commission of Fiji 2002). Milling technology has changed little over the past half century. The mills are 68 per cent owned by the government, and employ around 3,000 workerssome only during the half-yearly harvesting season. Depending on milling efficiency and the volume of throughput, total sugar production has ranged from 264,000 (in 1975) to 517,000 tons (in 1994) (annual production data is given in Table 11.3). ${ }^{8}$ The price paid to the growers for the cane is determined by a legislated formula, namely the Master Award, which apportions the average price received for the sugar produced between the Fiji Sugar Corporation and the grower. ${ }^{9}$

In spite of the favourable prices received for exports, the sugar industry has been in financial strife in the recent past. Fiji Sugar Corporation has recorded losses in each year from 1997 to 2002 achieving a record loss in 2001 of US $\$ 20.8$ million. Independent financial auditors for 2001 noted that Fiji Sugar Corporation retained its status as a 'going concern' only because the Fiji government underwrote its operations. Another commentator has observed that the Fiji Sugar Corporation 'exists very much at the Governments' pleasure' and, given the prevailing cost structure, the equity of investors in FSC would be 'rapidly destroyed' with the suspension of preferential access to the EU market (White 2004).

The growers have been in similar strife. The average cost of producing a ton of sugarcane is estimated at around US\$37 (Reddy 2004), but this figure varies considerably between farms. Rao (2004), using farm level data, shows that a farmer producing 160 tons of sugarcane earned an annual income gross of labour input of US\$1,202 (data for 2001). This puts the farmer in poverty given that the rural-household 'basic needs poverty line' is US\$115 per week (ADB 2003:9). This observation is consistent with an earlier study that suggested growers producing less than 200 tons of cane are likely to be in poverty (World Bank 1995).

If, as stipulated in the Master Award, 70 per cent of the total rents accruing from access to the preferential markets in 2001 were divided equally between 
the 22,000 growers, each grower would receive some US\$4900. On the basis of this allocation, Fiji Sugar Corporation would receive US\$32.4 million. Alternatively, each ton of sugarcane produced in 2001 earned US $\$ 38$ in rents alone. On the 70:30 formula the grower (together with the landlord) received approximately US $\$ 27$ per ton, while the balance of US\$11 went to the Fiji Sugar Corporation. Neither the Fiji Sugar Corporation nor the growers are reported to have made super-normal profits. The large rents transferred via preferential prices paid for sugar exports from Fiji can only be reconciled with the poor financial state of the industry by noting the extent to which rents are

Table 11.3 Sugar production statistics, 1971-2002

\begin{tabular}{|c|c|c|c|c|}
\hline Year & $\begin{array}{c}\text { No. of } \\
\text { contracts }\end{array}$ & $\begin{array}{c}\text { Area harvested } \\
\text { ('000ha) }\end{array}$ & $\begin{array}{c}\text { Cane delivered } \\
\text { ('000t) }\end{array}$ & $\begin{array}{l}\text { Sugar produced } \\
\text { ('000t) }\end{array}$ \\
\hline 1971 & 15,548 & 47 & 2,545 & 323 \\
\hline 1972 & 15,612 & 44 & 2,238 & 303 \\
\hline 1973 & 16,533 & 46 & 2,496 & 301 \\
\hline 1974 & 16,546 & 45 & 2,151 & 272 \\
\hline 1975 & 17,264 & 45 & 2,160 & 264 \\
\hline 1976 & 17,667 & 47 & 2,283 & 286 \\
\hline 1977 & 18,395 & 52 & 2,674 & 362 \\
\hline 1978 & 18,456 & 54 & 2,853 & 347 \\
\hline 1979 & 19,152 & 62 & 4,063 & 473 \\
\hline 1980 & 19,700 & 66 & 3,360 & 396 \\
\hline 1981 & 21,000 & 66 & 3,931 & 470 \\
\hline 1982 & 21,574 & 69 & 4,075 & 487 \\
\hline 1983 & 21,880 & 59 & 2,203 & 276 \\
\hline 1984 & 22,130 & 69 & 4,290 & 480 \\
\hline 1985 & 22,159 & 70 & 3,042 & 341 \\
\hline 1986 & 22,182 & 69 & 4,109 & 502 \\
\hline 1987 & 22,255 & 66 & 2,960 & 401 \\
\hline 1988 & 22,127 & 64 & 3,185 & 363 \\
\hline 1989 & 21,771 & 71 & 4,099 & 461 \\
\hline 1990 & 21,334 & 70 & 4,016 & 408 \\
\hline 1991 & 24,479 & 73 & 3,380 & 389 \\
\hline 1992 & 23,334 & 73 & 3,533 & 426 \\
\hline 1993 & 23,454 & 74 & 3,704 & 442 \\
\hline 1994 & 23,264 & 74 & 4,064 & 517 \\
\hline 1995 & 22,449 & 74 & 4,110 & 454 \\
\hline 1996 & 22,304 & 74 & 4,380 & 454 \\
\hline 1997 & 22,100 & 73 & 3,280 & 347 \\
\hline 1998 & 22,146 & 57 & 2,098 & 266 \\
\hline 1999 & 22,178 & 65 & 3,958 & 377 \\
\hline 2000 & 22,179 & 63 & 3,786 & 341 \\
\hline 2001 & 21,882 & 66 & 2,805 & 293 \\
\hline 2002 & 21,246 & 65 & 3,423 & 330 \\
\hline
\end{tabular}

Source: Fiji Bureau of Statistics,various issues. Current Economic Statistics Bulletin, FBS, Suva. 
dissipated. This is the case of an industry that has moved up its average cost curve, exhausting all the rents through increased costs of production.

Fiji has strong incentives to ensure that the preferential quotas, particularly those to the European Union, are met. The substantial value of rents implicit in the preferential arrangement, together with the penalties in the form of loss of the preferential quota in the event of being unable to meet supply targets, induce production well above the preferential quota. Except for 1997, a record drought year, Fiji has always met its preferential quota. For the decade to 2001 , production on average exceeded the preferential quota by around 60 per cent. While the European Union is the major market, accounting annually for 200,000 tons of sugar exports, another 10,000 tons is exported to the United States, and local consumption accounts for approximately 40,000 tons. Production in excess of the preferential quotas is sold at world market prices under bilateral access agreements with Canada, China, Japan, South Korea, Malaysia, Indonesia and New Zealand. Any remaining production is sold on the world market. There is no protection for sugar within the domestic market, thus the price paid at home reflects the world market price.

\section{RENTS AND EFFICIENCY IN SUGAR PRODUCTION}

The value of rents, $V$, implicit in a preferential arrangement can be estimated as the product of the preference margin, $m$, and the preferential quota, $\bar{Q}$ when the preference is fully utilised. That is

$$
\begin{aligned}
& \mathrm{V}=\left(\mathrm{P}^{\mathrm{EU}}-\mathrm{P}^{\mathrm{W}}\right) \overline{\mathrm{Q}} \equiv \mathrm{m} \overline{\mathrm{Q}}, \text { for } \mathrm{Q}^{\mathrm{X}} \geq \overline{\mathrm{Q}} \\
& \mathrm{V}=\left(\mathrm{P}^{\mathrm{EU}}-\mathrm{P}^{\mathrm{W}}\right) \mathrm{Q}^{\mathrm{X}} \text { otherwise. }
\end{aligned}
$$

where $\bar{Q}$ is the level of the quota and $Q^{X}$ is total exports. Since the marginal value of rents of production above the preferential quota is zero, a rentmaximising monopoly under conditions of certainty (as shown by Equation 11.1) will produce output just equal to the preferential quota. As noted above, this obviously has not been the case. The industry as a whole loses rents when aggregate output falls short of the preferential quota. Uncertainty with respect to realised output given unpredictable weather conditions (including tropical cyclones) during the growing season has encouraged above-quota production.

Rent dissipation takes place through the following four channels. First, the market structure in the form of a monopoly miller with a competitive smallholder 
farm sector has encouraged production in excess of the quota. Above-quota production, while raising unit production costs, has led to a fall in the average price received, given that production in excess of the preferential quota is sold at the much lower world market price. A monopoly miller that coordinates the growing and harvesting of sugarcane has an incentive to see that the preferential quota is fulfilled. The competitive nature of the smallholder sugarcane-growing sector encourages production in excess of the farm quota in the form of 'farm basic allotment'. The preferential rent forms a common pool that individual farmers access via their farm output. Where one farm's output in excess of the 'farm basic allotment' offsets that of another, as happens given the large variability in weather conditions across the sugarcane-growing regions, the 'lucky' farmer earns super-normal profits. The payment formula, based on averages, and without penalties for production in excess of the 'farm basic allotment' other than the lower price faced by all growers, encourages production beyond the farm allocations. ${ }^{10}$

Second, rents have been dissipated by milling inefficiencies. Technical milling efficiency, in terms of tons of sugarcane crushed to produce a ton of sugar (tcts), has deteriorated by approximately 30 per cent over the 30 years to 2002. This has happened as the (real) price of sugar, in 1995 prices, has fallen (see Figure 11.2). This observation is confirmed by regressing tcts on a time trend and the price of sugar. The estimates show that the number of tons of cane crushed to produce a ton of sugar, controlling for the price of sugar, increased at a rate of approximately one per cent per annum. This result, reported in Table A11.1 in the appendix, is robust to a number of alternate specifications. The Fiji Sugar Corporation, moreover, has an incentive to achieve the preferential quota but has little incentive to produce sugar in excess of the preferential quota. Anecdotal evidence supports this conclusion as the frequency of mill breakdowns has increased whenever throughput has been abnormally high.

Third, rents have been used to sustain favourable employment conditions within sugar manufacturing. Prasad and Akram-Lodhi (1998) report that high union densities and a well established industrial relations framework have ensured that FSC factory and field employees have benefited from both preferential prices and the sales security guaranteed by the Protocol. ${ }^{11}$

While Fiji Sugar Corporation is mandated to pay the minimum legislated wages, which for manufacturing sector workers for 1999 was US $\$ 97$ per week, 
Figure 11.2 Milling efficiency and price of sugar

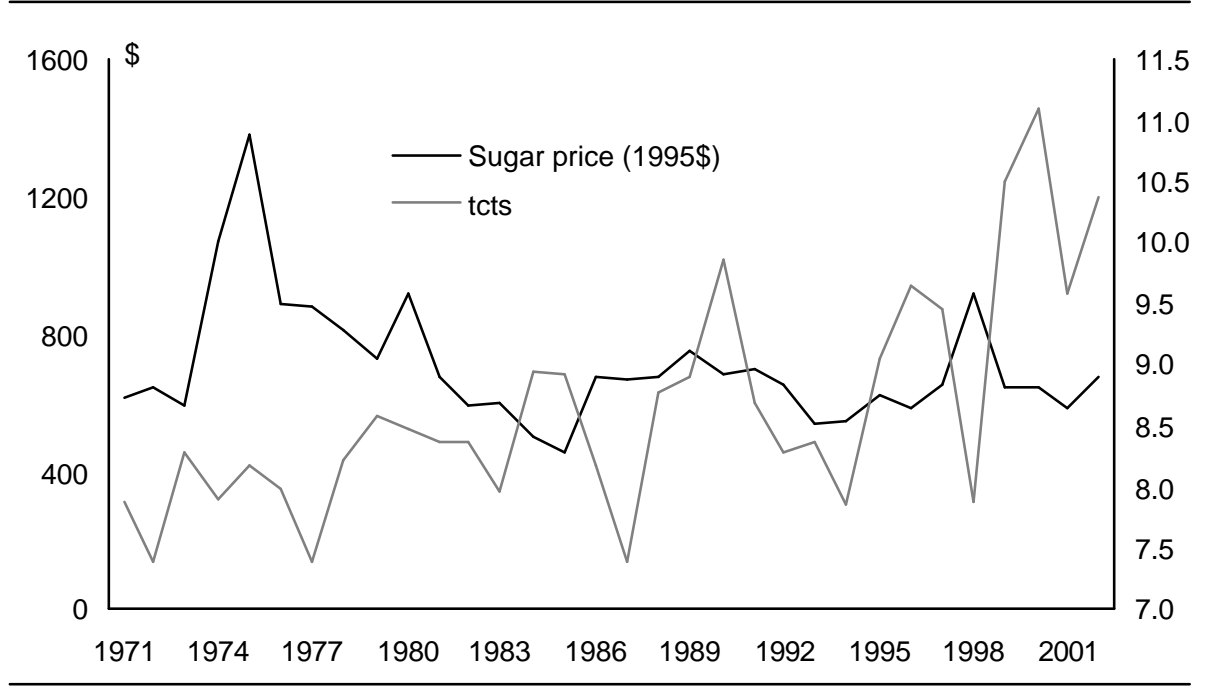

Source: Author's calculations based on data from Current Economic Statistics (various issues), Suva, Fiji.

the non-unionised cane cutters earned an average income of US\$62 per week during the six-monthly harvesting season (wage data from Fiji Bureau of Statistics 2004 and Reddy 2004). As a large formal sector employer, the Fiji Sugar Corporation with its inflated wages would, moreover, draw the most productive workers whilst raising wage costs for the rest of the private sector. In 1999, payroll costs for the Fiji Sugar Corporation amounted to 55 per cent of total operating costs, a figure considered to be 'too high' by White (2004).

Fourth, rents have been dissipated via expansion of sugar cane production onto marginal land and/or those distant from the mills. Productivity within the Fiji sugar industry compares unfavourably with other sugar-producing nations. As an example, average cane output in Fiji at 19.6 tons per acre compares with a figure of 31.9 for Mauritius, 35.4 for Queensland, and 43.8 for Hawaii (data from Reddy 2004). The expansion of area under cultivation has meant that the average cost of delivering cane to the mills has risen over time, thus dissipating some of the rents. Land values within the sugarcane growing districts, moreover, have risen with the expansion of area under cultivation. With land rentals set at 6 per cent of the unimproved capital value, the landowners have shared in the rents from sugarcane farming. 
The analysis thus far has been of a partial equilibrium nature. The general equilibrium effects, including the terms of trade effects, can be large if preference erosion leads to large dislocation of factors of production. Two studies that model the general equilibrium effects of trade liberalisation for Fiji show losses from preference erosion that are less than the value of the rents implicit in the subsidy. McDonald (1996) simulates the impact of Uruguay Round agricultural trade liberalisation; the results show a net welfare loss to Fiji equivalent to 2.52 per cent of GDP. Levantis et al. (2004) use a dynamic CGE model to simulate the impact of the removal of the subsidies implicit in the preference margin coming up with an annual loss of 1.1 per cent of GDP. Given that rents from the sugar preferences account for approximately 5 per cent of GDP and their loss is estimated to reduce welfare by a maximum of 2.5 per cent, the buy-out of the preferential arrangement will still deliver a net benefit equivalent to 2.5 per cent of GDP. At best, the preferences for Fiji sugar exports have played only a marginal role in assisting development, ${ }^{12}$ a claim supported by the broad literature that shows that economic performance is determined principally by domestic policies (see Panagariya 2003). Access to preferential rents, moreover, may have impeded resource flows into the more dynamic sectors, thus constraining growth of aggregate output.

\section{POLICY IMPLICATIONS}

Given the evidence, it is doubtful whether preferential access for Fiji sugar into the European Union and the United States has helped create a viable industry. It may, however, have put off the death of an unviable one. It is also debatable whether the preferential arrangement has been good for Fiji's development. The dissipation of rents suggests that lump-sum transfers would have been a superior alternative in assisting development. Since the sugar preferences will erode, possibly rapidly, over the next decade, the question for policymakers is how to induce change to a subsidy free environment with minimal adjustment costs.

Given that rents from preferential access have been dissipated, their loss will reduce the rent-dissipating activities that have developed and thus improve economic efficiency. The gains, however, will materialise only after all the adjustments have taken place. In the interim, preference erosion will impose adjustment costs, particularly on immobile factors such as land currently being used for growing sugarcane and the labour and capital facing dislocation. A generation of sugarcane farmers with little in the way of transportable skills 
will face serious declines in their income from an already low level. The sugarcane cutter who now earns some US\$62 per week in the harvesting season is, in the immediate term, likely to be left without a job. For many smallholders, expiring land leases are only going to compound these problems (see Reddy and Yanagida 1998; Levantis et al. 2003; Prasad and Narayan 2004). Many displaced farmers are reported to be moving into squatter settlements around the urban centres, and this social dislocation is creating its own problems.

Two studies have argued for more time in the withdrawal of preferences on the grounds of social and economic dislocation. Oxfam (2002:28) recommends that the European Union ' $[\mathrm{m}]$ aintain quotas for the African, Caribbean and Pacific preferential sugar imports' while Prasad and Akram-Lodhi (1998:39) argue for the continuation of export subsidies through the sugar protocol claiming that, "in the specific case of Fiji, trade is a more effective form of development cooperation'. The latter argues for a restriction on 'third country competition' for sugar exports to the European Union to allow farmers to improve efficiency and diversify into other products. I disagree with these recommendations. Such a program is likely to be counterproductive as it will prevent efficiency improvements, discourage diversification, and, most importantly, create incentives for lobbying for domestic subsidies when those from abroad expire. Grossman and Helpman (1996) provide a model that rationalises lobbying effort for protection by the incumbents in a sunset industry. Ozden and Reinhardt (2002) show that countries removed from GSP adopt more liberal trade policies than those remaining eligible and that greater utilisation of the preferences raises the resistance to trade liberalisation.

There is little doubt that the preferences will fall. The abolition of the preferential price arrangement is certain given the European Union's commitment to abiding by the WTO process. The loss of the subsidy, unless prepared for well in advance, will create serious adjustment pains for the economy as a whole. The incentives for managing the adjustment process are, therefore, strong. The EU Economic Partnership Arrangements contain measures to support adjustments to liberal trade as per WTO commitments (European Commission 2002). Article 68 of the Cotonou Agreement provides for '[a] system of additional support in order to mitigate the adverse effects of any instability in export earnings, including in the agricultural and mining sectors... within the financial envelope for support to long-term development', 
with island and land-locked economies identified as deserving favourable treatment. ${ }^{13}$ Short-term respite from preference erosion can also be sought via the recently approved IMF Trade Integration Mechanism (see IMF 2004). Fiji could, at least in the short term, seek quota-free access to the EU market while the preference margin is lowered. Export income in this scenario would increase so long as the preferential price does not fall by more than 25 per cent, ${ }^{14}$ but the relief provided will only be short term.

A permanent solution to preference erosion would involve measures that induce adjustment with compensation for the costs incurred. A self-funding mechanism, based on the value of rents implicit in each ton of sugar produced for the preferential market for the remaining life of the preferential arrangement could be developed as follows. Assume that the preferences would fall in two steps: first, by 40 per cent in three years' time followed by a complete withdrawal in another seven years. Furthermore, assume a preference margin of US\$600 per ton and a discount rate of 5 per cent. These assumptions imply that the net present value of rents implicit in each ton of sugar produced over the remaining life of the preferential agreement is US\$3,005. The preferential quota can be bought at this price; that is, the preferences can be bought out with rents implicit in the remaining life of the arrangement. The grower producing 160 tons of sugarcane, of which 100 tons are destined for the preferential market, would, on the basis of the 70 per cent share of rents, receive US $\$ 21,035$. A rate of return of 5.7 per cent is all that is necessary for this sum to generate an income equal to the US\$1,202 that the farmer earned, gross of labour input, from cane farming. On the assumption that 200,000 tons of sugar has access to the preferential market, the FSC would receive US\$180 million. This amount could be used to fund the restructuring to a subsidy-free environment, or, if necessary, winding down of the industry.

It is possible that the Fiji sugar industry will become non-viable following the withdrawal of preferences. One commentator has suggested that

a realistic evaluation of the industry's long term viability is needed. The most appropriate policy to pursue may well be one that enables the orderly winding down of the industry and its ultimate closure (White 2004:300).

Rather than spend further resources in evaluating the viability of the industry, the proposal put forward here allows industry itself to make this choice of its own volition. Market mechanisms are used to assess and decide the viability of 
the industry. The calculations made in this chapter suggest that whatever the outcome, the industry as a whole and the economy more generally benefit from the policy interventions suggested.

The upfront payment of rents implicit in the remaining life of preferential access has two major advantages over an extension of the current arrangements as suggested by Oxfam (2002) and Prasad and Akram-Lodhi (1998). First, the lump-sum payment creates an incentive for growers and the miller to adjust to a subsidy-free environment as early as possible. Waiting under this scenario is costly, particularly when preferential rents are dissipated. This is in sharp contrast to a push for extension of the deadline for withdrawal of preferences. Second, the market is used to induce adjustment with payments being fully funded from the remaining life of the preferential arrangement. The difficulty here will be in getting the European Union to pay the rents as a lump sum, but the Economic Partnership Agreements and Article 68 of the Cotonou Agreement do entertain such a possibility.

\section{CONCLUSIONS}

Preference erosion results when exporters with privileged access into industrialcountry markets lose their competitive advantage as barriers to international trade are lowered under the Most-Favoured Nation (MFN) principle of the WTO. Active discrimination in favour of a select group of developing countries by their industrial country partners, permitted under 'Special and Differential Treatment' of GATT/WTO, is facing the closest scrutiny as the case against 'aid through trade' becomes increasingly convincing (see Panagariya 2003 and Hoekman and Ozden 2005). The African, Caribbean, and Pacific group of countries faces the prospect of losing preferential access to the EU market as the latter liberalises its trade under its WTO commitments. The case of Fiji sugar is used here to highlight both the challenges posed by preference erosion and policy options available to minimise the adverse consequences.

I show that rents from preferential access have been dissipated via inefficiencies in the growing of sugarcane, milling of the crop, and through higher wages for the unionised sector. Such dissipation is indeed not peculiar to the Fiji sugar industry but is a common phenomenon across industries and countries. Horstman and Markusen (1986), for example, have shown that subsidies and tariffs that lead to inefficient entry have negative welfare 
consequences. Snape (1963) and Johnson (1966) had made similar predictions with respect to interventions in the global sugar market. The erosion of the preferences, therefore, will be efficiency enhancing, as it will remove the rents that fund the inefficiencies in the first place. The aforementioned gains, however, will only accrue following adjustment to a subsidy-free environment; dislocation of capital, labour and land from sugar production in the interim will incur costs. Such costs can be contained with the provision of adjustment assistance. Resources for the assistance can be tapped from rents implicit in the remaining life of the preferential arrangement. Ozden and Reinhardt (2002) show that 'nonreciprocal preferences have the perverse effect of delaying trade liberalisation'; preference erosion, therefore, may induce unilateral liberalisation. Declining industries have a reputation for successfully playing the political system (see Grossman and Helpman 1996), so achieving the transformation above will not be easy.

The case of Fiji sugar has been used in this paper to address the specific problem of preference erosion. While the policies discussed here are particular to Fiji sugar, the principles have broader applicability. Fiji, for example, is facing preference erosion with respect to clothing exports to Australia and New Zealand under the South Pacific Regional Trade and Economic Cooperation Agreement (SPARTECA). ${ }^{15}$ Sugar exports from Mauritius to the European Union are in a similar predicament to those of Fiji. The idea of trade adjustment funded with rents implicit in the remaining life of preferential access arrangements could be used more generally to fund costs of adjustment and induce restructuring to a subsidy-free environment.

\section{ACKNOWLEDGMENTS}

Helpful comments on an earlier draft of this paper from Malcolm Bosworth and Rod Duncan are gratefully acknowledged with the usual disclaimer.

\section{NOTES}

1 The small country assumption has been invoked here. That is, it has been assumed that exports of sugar from Fiji and Mauritius have no impact on the world market price.

2 African, Caribbean and Pacific states include Barbados, Belize, Congo, Cote d'Ivoire, Guyana, Fiji, Jamaica, Kenya, Madagascar, Malawi, Mauritius, St Kitts and Nevis, Swaziland, Tanzania, Trinidad and Tobago, Zambia and Zimbabwe. 


\section{Pacific Island Regional Integration and Governance}

3 Stocks of sugar held in Europe fell by 0.4 million tons, accounting for the balance between aggregate supply and demand (data from Oxfam 2002:8).

4 This was the Punta del Este Declaration of Ministers of Trade made in September 1986 (quoted from http://www.acpsugar.org/eusugar1995review.htm [accessed 18 October 2004]).

5 The EU appealed this decision on the grounds that the decision was based 'on an erroneous interpretation of the WTO provisions on agricultural export subsidies and inconsistent with the obligation of good faith'. The WTO's Appellate Body upheld an earlier Panel decision that the operation of the EU sugar regime was inconsistent with its obligations under the WTO Agreement on Agriculture.

6 The Fiji Sugar Corporation has small farms near its mills but they are used primarily for research.

7 In sharp contrast to Mauritius, irrigation has not been used in farming sugar cane. The difference could be explained by the fact that 55 per cent of sugarcane in Mauritius is produced by the sugar mills themselves on farms ranging in size from 700-5,500 hectares in size and that all land is privately owned.

8 By international standards, Fiji is a high-cost producer. The Fiji prime minister has publicly stated that cane yield per hectare in Fiji is the second lowest and sugar yield the worst amongst the 20 African, Caribbean, and Pacific (ACP) sugar-producing states (FijiSUN, 6 October 2004). The costs of producing a ton of sugar at the four mills, according to the prime minister, in Fiji dollars are 340, 320, 230, and 160 at the Penang, Lautoka, Labasa, and Rarawai mills, respectively.

9 The Master Award assigns 70 per cent of the proceeds from sugar exports of up to 325,000 tons to growers. This share rises to 72.5 per cent for exports between 325,000 and 350,000 tons, and to 75 per cent for exports greater than 350,000 tons (see Reddy 2004).

10 Alternative strategies for addressing the production uncertainty include buying insurance and building buffer stocks. Neither of these is realistic, however, as the first is not yet available, and the value of the second is questionable given the international experience with commodity marketing boards.

11 Establishing that mill workers appropriate some of the preferential rents requires the estimation of wage equations as in Krueger and Summers (1988) and Katz and Summers (1989). Data for such analysis, however, is absent. Workers hired on farms run by the Fiji Sugar Corporation earn wages well in excess of their counterparts in adjoining fields run by private operators. This has led to queuing for such opportunities.

12 This observation is consistent with international evidence that shows 'the track record of preferences to-date gives little reason to conclude that they will make a perceptible difference to growth and poverty reduction in the beneficiary countries' (Panagariya 2003). This same point was made much earlier by Whalley (1990). 
13 The quote is from: http://europa.eu.int/comm/development/body/cotonou/agreement/ agr30_en.htm [accessed 5 May, 2005].

14 The price received under the Protocol is approximately $\$ 1000$ per ton; the average price currently received for exports is $\mathrm{F} \$ 750$.

15 SPARTECA is a non-reciprocal trade agreement where Australia and New Zealand offer dutyfree and concessional access for several products from the developing island member countries of the South Pacific Forum. The agreement was signed in Kiribati on 14 July 1980 at the Eleventh Meeting of the Forum and came into effect from 1 January 1981. The current list of signatories to SPARTECA includes Cook Islands, the Federated States of Micronesia, Fiji, Kiribati, Marshall Islands, Nauru, Niue, Papua New Guinea, Solomon Islands, Tonga, Tuvalu, Vanuatu and Western Samoa.

\section{APPENDIX}

Table A11.1 Estimates of milling efficiency, 1971-2002

\begin{tabular}{lcc} 
Variable name & Model 1 & Model 2 \\
Constant & 2.17 & 2.20 \\
& $(4.94)^{* *}$ & $(8.71)^{* *}$ \\
$\ln$ (sugar price) & -0.22 & \\
& $(-0.33)$ & \\
$\ln$ (cane price) & & -0.041 \\
& & $(-0.69)$ \\
Time & 0.007 & 0.0069 \\
& $(4.62)^{* *}$ & $(4.17)^{* *}$ \\
Number of observations & 32 & 32 \\
Adjusted R & 0.43 & 0.44 \\
Durbin Watson d-statistic & 1.73 & 1.79 \\
\hline
\end{tabular}

Notes: Dependent variable is tons of cane crushed to produce a ton of sugar (tcts), annual data from 1971-2002 used. Sugar and cane prices are in 1995 dollars; ** denotes significant at the 5 per cent level. 


\section{COMMENT}

\section{Alan Winters}

This is a nice chapter continuing, as Satish Chand notes, a long and noble tradition of work on sugar trade policy. I have three sets of comments-on the domestic industry, the proposed redistribution scheme and the global context. First, however, I want to clarify the term 'rent'.

Consider Figure 1 below in which an industry has a rising marginal cost curve and faces given prices for its sales. The world price is $P_{W}$ but, because of preferences, the country actually receives $P_{P}$. Satish defines rent as $q^{*}\left(P_{P}-P_{W}\right)$, that is, area $(\mathrm{a}+\mathrm{b})$, but strictly this is 'quota rent'. Assuming no other distortions, Ricardian rent is $(\mathrm{a}+\mathrm{c})$ - the earnings in excess of those necessary to keep factors in their current employment. Relative to quota rent, this adds one area of rent for highly efficient firms even with free trade, and removes one as marginal costs increase through the policy-induced expansion of output.

The distinction between the two concepts is useful not only for interpreting this chapter but for several others in this volume. The answer to 'how much does supply fall as rents are reduced?' is zero for Ricardian rent (by definition), but not for quota rent. Similarly, does the payment of super-normal wages represent the 'dissipation' of rent? Maybe for quota rent, but on Ricardo's concept, it is merely the transfer of rent to a different part of society. Finally, will free trade eliminate rents? Yes for quota rents, but not for Ricardian rents. I don't wish to be prescriptive about which terminology is correct, but I do want us to be clear what it is we are analysing. 
Figure C11.1 Rents in a model industry

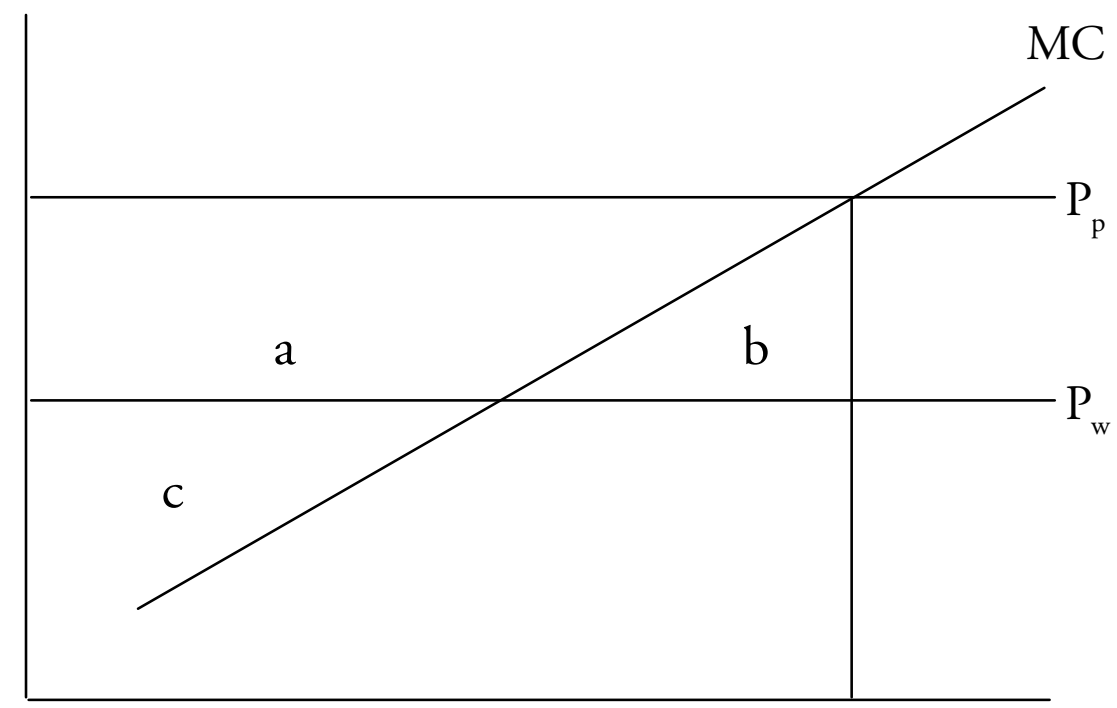

\section{THE DOMESTIC INDUSTRY}

Throughout the chapter, I found myself wondering about the role of the mills in the Fijian industry. According to the prime minister their costs diverge by a factor of greater than two. Why do the less efficient ones remain in business? Do they pay lower prices to farmers or receive higher prices for output? How is the Fijian quota in the European Union allocated between them? To the extent that prices are fixed and quotas allocated administratively, and if managers are not paid according to profits, there is little incentive for mills to be efficient, and their rising crush ratios are not surprising. Thus a good part of the rent dissipation Satish identifies probably arises from poor policy-the inefficient allocation of the quota. That is, Fiji could earn higher (Ricardian) rents merely by allowing efficient mills to expand at the expense of less efficient ones.

There is another policy distortion that appears to raise costs. Mills apparently pay an average price for any quantity of sugar delivered, so that, as Satish shows, farmers can increase their own share of the basically fixed revenue by producing and selling more. If the EU quota is $Q^{*}$ and over-quota sales to the mills are $Q$; total farm revenue is $0.7^{*}\left(P_{W} Q+P_{P} Q^{*}\right)$ and price per unit 
$0.7^{*}\left(P_{W} Q+P_{P} Q^{*}\right) /\left(Q^{*}+Q^{*}\right)$. This clearly exceeds $P_{W}$ and so encourages production to a point where $M>P_{W}$ and, in this case, apparently leads output to exceed $Q^{*}$. More rational would be to agree farm-level quotas, $q_{i}$, which would command price $0.7^{*} P_{P}$ and for mills to purchase any additional units at a market clearing price. Because of the production uncertainty and the high costs of failing to supply $Q^{*}$ to the European Union, the sum of the $q_{i} s$ would optimally exceed $Q^{*}$, but beyond that safety margin the marginal incentives would be appropriately aligned. Whenever the sum of farmers' within-quota sales exceeded $Q^{*}$, the over-quota market price would be $0.7^{*} P_{W}$, but if ever the sum fell short, the price would rise above $0.7^{*} P_{P}$ to reflect the value of meeting $Q^{*}$ in order for Fiji to keep its overall quota in the European Union. Farmers could then make their own output decisions according to their risk aversion and the incentive for excess (and hence high-cost) production beyond the point where $M C$ equalled expected $M R$ (the price for marginal units) would be eliminated. This too would allow Fiji to make greater rents out of any given EU price/quota regime.

\section{THE REDISTRIBUTION}

Around one-quarter of Fiji's jobs stem for the sugar industry. From this I infer that a (perhaps the) major concern over preference erosion is social, and we need to ask whether Satish's scheme will satisfy social (distributional) objectives. This depends on details of its allocation. For example, what is the quantity base on which farmers' interests are to be bought out—a share of $Q^{*}$, or, say, their actual $q_{i}$ in a base year? If they are to sell their interest, it has to be welldefined. How does one ensure that some of the capital is transferred to the casual labourers who do the cutting-or, indeed, to any other labour. How do we ensure mill-owners compensate their workers, and does their 30 per cent share of the revenue cover that obligation?

There are also questions about whether all the capital sum that Fiji receives from the European Union should be redistributed or whether the government should hold some back to provide public goods or a steady flow of income through time. The latter issue is essentially that addressed by compulsory pensions. If individuals squander their capital compensation, they will suffer in future. But since a humane society will not let them starve, some of the burden of their profligacy will fall on society. Relatedly, if all the money is distributed, what ensures sugar producers/workers will not lobby for new 
support after a few years because of the adjustment costs they are still bearing? This time-consistency problem is a major issue for capital compensation schemes wherever policy is adjustable through time.

On the other side of the coin, of course, Fiji's rather blemished governance record has raised issues about the security of investments, either public or private. Moreover, whether the income flow is from private investments or a public pension, there is good reason to worry about the social health of a largely rentier or transfer-funded society.

\section{THE GLOBAL CONTEXT}

Finally, two small points. First, the Cotonou Agreement refers to additional support 'within the financial envelope'. I interpret this as implying that buying out the sugar quota will be at the expense of some other aid flow. This may not be desirable. Second, Satish analyses the erosion of Fiji's preferences in isolation, but in fact we are really talking about a regime change here. All sugar producers will be affected, so one really needs to conduct the exercise at a different $P_{W}$ 